\title{
Variation of Near Fault Ground Motion Intensity Measures Due to Filtering
}

\author{
${ }^{* 1}$ Esengul Cavdar ${ }^{1}$ Gokhan Ozdemir and ${ }^{2}$ Ozkan Kale \\ ${ }^{1}$ Department of Civil Engineering, ESQUAKE, Seismic Isolator Test Laboratory, Eskisehir Technical University, Turkey \\ ${ }^{2}$ Faculty of Engineering, Department of Civil Engineering, TED University, Turkey
}

\begin{abstract}
Ground motions recorded at near fault zones ensures rich low frequency contents, and high velocity pulse signals which may result in large shear force and displacement demands in structural elements. During the recording of these seismic events by accelerometers, low-frequency noise may sometimes accompany the signal. Thus, extracting this noise from recorded acceleration data is a crucial step of post-processing performed prior to use of acceleration time series in structural analyses for both design or assessment purpose. The objective of this study is to assess the effect of high-pass filtering on the intensity measures of ground motions. A set of near fault ground motions that comprises both pulse-like and non-pulse like characteristics were selected and they were subjected to filtering for various cutting frequency contents. As a function of filtering, variation in several intensity measures of filtered ground motions namely, PGD, PGV, PGA, PGV/PGA and significant duration were analyzed. It is revealed that changing the cutting frequency of high pass filtering considerably changes the intensity measures of ground motion records.
\end{abstract}

Key words: High-pass filter, near fault ground motion, intensity measure.

\section{Introduction}

Ground motions recorded at near fault zones comprise rich low frequency content, high velocity, and sometimes impulsive characteristics. The existence of low frequency noise in ground motion records can significantly affect the spectral ordinates and resulted in computing unreliable spectral quantities. The high-pass filtering is widely used to process strong motion records to remove the low frequency noise, and also eliminate permanent ground motion displacement [1]. Hence, using high pass filtered seismic inputs influences the seismic response of structures. In the literature several works have been conducted on the effect of low frequency noise on reliable elastic spectral displacement calculations [2-4]. Abrahamson and Silva [2] proposed to use elastic spectral ordinates for periods up to $0.8 \mathrm{fc}$ (high-pass filter frequency). Akkar and Bommer [4] recommended more elaborated empirical factors as a function of fc, filter type (analog or digital) and site condition of the recording. To assess the filtering effects on the inelastic oscillator response, Kale [5] investigate the influence of high-pass filter cut-offs on the nonlinear spectral displacements by considering different hysteretic models by mimicking various levels of inelasticity. Burks and

\footnotetext{
* Corresponding author: Address: Eskisehir Technical University, ESQUAKE, Seismic Isolator Test Laboratory, Eskisehir, TURKEY. E-mail address: esengulcavdar@eskisehir.edu.tr, Phone: +90 22232135 50 (7289)
} 
Baker [6] performed an analytical study on the collapse capacity of nonlinear single degree of freedom system with varying fling properties. Given the relevance of the results obtained, they concluded that high pass acausal filter has a negligible effect on the collapse capacity of nonlinear SDOF system, if the cutting frequency interval is away from the pulse or structural periods. On the other hand, to calculate the effect of filtering on the multi degree of freedom systems, Buyco et al. [7] conducted a comprehensive study by performing incremental dynamic analysis to evaluate collapse capacity of three mid- to high-rise building models. Authors revealed that removing long period noise with high pass filtering may result in over-estimated collapse predictions by more than $50 \%$.

During the ground motion processing, the type of the filter is less crucial than the selection of cutting frequency content in which the Fourier amplitude spectrum shows a low signal to noise ratio [3]. In literature, there are studies that investigates how the filter order and cutting frequency effect the seismic input properties. For instance, study conducted by Zerva and Liao [8] revealed that processed ground motion shows more sensitivity to the low cut-off frequency intervals than the higher frequency cut-offs. Falamarz-Sheikhabadi and Zerva [9] investigated the effect of low frequency cut-off filtering on reliability analyses. In their study, authors showed that uncertainties in low frequency cut-off affects the peak ground motion amplitudes such as peak ground displacement (PGD) and peak ground velocity (PGV). It is reported that an increase in low frequency cut-off generally leads to reduced PGD and PGV. Xue et al. [10] investigates the variation of elastic and inelastic response spectra obtained for high pass filtering with different cutoff frequencies. Authors reported that impulsive characteristics of seismic inputs recorded at near fault zones are influenced by high pass filtering.

In this study, it is intended to show the sensitivity of intensity measures such as PGD, PGV, peak ground acceleration (PGA), PGV/PGA and significant duration to the low frequency cut-off filtering. Accordingly, a set of near fault pulse like and non-pulse like ground motions were selected and high-pass filtering was applied to each record with twenty different cut-off frequencies. Then, intensity measures of seismic inputs were calculated for filtered ground motions. Variation of intensity measures due to filtering was discussed in a comparative manner. In the comparisons, in addition to intensity measures computed for raw data (unfiltered) and filtered motions, the ones computed for the publicly available NGA-West 2 database of PEER [11] are also presented in order to provide a basis for engineers to understand the significance of filtering.

\section{Ground Motion Processing for Low Frequency Noise}

Twelve pairs of near-fault ground motion records were selected with similar characteristics of moment magnitude $\left(\mathrm{M}_{\mathrm{w}}\right)$ and source-to-site distance $\left(\mathrm{R}_{\mathrm{rup}}\right)$. Accordingly, $\mathrm{M}_{\mathrm{w}}$ is greater than 6.5, $\mathrm{R}_{\text {rup }}$ is lower than $20 \mathrm{~km}$. In order to investigate the effect of filtering on ground motion impulsive properties, both pulse- and non-pulse like seismic records are considered. Selected motions and their characteristics are presented in Table 1. 
Table 1. Selected ground motions for high pass filter processing

\begin{tabular}{cccccccc} 
No & RSN \# & Earthquake & Mw & Station & Rrup $(\mathbf{k m})$ & Pulse/Nonpulse & Tp (s) \\
\hline 1 & 160 & Imperial Valley & & Bond Corner & 2.66 & Non-pulse like & - \\
2 & 161 & Imperial Valley & & Brawley Airport & 10.42 & Pulse like & 4.396 \\
3 & 170 & Imperial Valley & & EC Co Center FF & 7.31 & Pulse like & 4.417 \\
4 & 179 & Imperial Valley & \multirow{2}{*}{6.53} & El Centro Array \#4 & 7.05 & Pulse like & 4.788 \\
5 & 180 & Imperial Valley & & El Centro Array \#5 & 3.95 & Pulse like & 4.130 \\
6 & 183 & Imperial Valley & & El Centro Array \#8 & 3.86 & Non-pulse like & - \\
7 & 173 & Imperial Valley & & El Centro Array \#10 & 8.6 & Pulse like & 4.515 \\
8 & 821 & Erzincan & \multirow{2}{*}{6.69} & Erzincan & 4.38 & Non-pulse like & - \\
9 & 1158 & Kocaeli & \multirow{2}{*}{7.51} & Duzce & 15.37 & Non-pulse like & - \\
10 & 1176 & Kocaeli & & Yarimca & 4.83 & Pulse like & 4.949 \\
11 & 1605 & Duzce & \multirow{2}{*}{7.14} & Duzce & 6.58 & Non-pulse like & - \\
12 & 1602 & Duzce & & Bolu & 12.04 & Pulse like & 0.882 \\
\hline
\end{tabular}

For the selected ground motion records, raw data (unfiltered acceleration records) are considered to observe the distortion on ground motions after filtering process. Also, NGA-West 2 records for all seismic inputs mentioned in Table 1 are downloaded from PEER strong motion database [11] in order to compare the differences between applied low frequency cut-off interval used in this study and that of NGA-West2 methodology.

\subsection{Processing methodology}

The processing of seismic input to remove low frequency noise is implemented by means of high pass filtering. For this purpose, the mean removed acceleration time series are firstly obtained following the procedure explained in Akkar and Bommer [4]. Then, the ground-motion records listed in Table 1 are high-pass filtered by employing 4-pole/4-pole acausal Butterworth filter [4,12] for a set of randomly generated $f_{c}$ values. The subjective decisions of the researchers are considered in this way while selecting the high-pass filter cut-off values. The high-pass filter frequency interval is determined separately for each record by considering Fourier amplitude spectra (FAS) of mean removed records. The number of $f_{c}$ values generated for the filtering is selected as 20 . The Latin Hypercube Sampling method [13] is used for the random generation of uniformly distributed filter cut-off frequencies. In this approach, the cumulative distribution of the sample is stratified into $\mathrm{N}$ equally sized intervals and the data is generated for each interval. This way, the sampling is forced to represent the target probability distribution.

The plots displayed in Figure 1 are the Fourier amplitude spectra of a high pass filtered record with different filter cut-off frequencies. The processed records are represented in grey color whereas the mean removed record is shown in red color. The FAS curves show how the selected high-pass filtering values affect the lower-end frequency content of a chosen record. The straight line (cyan color) on the left-hand side of the figure shows the $\mathrm{f}^{2}$ gradient, which is the theoretical decay rate of low-frequency components in an accelerogram. In this vein, part of the FAS curve of mean 
removed record at left-hand side of the $\mathrm{f}^{2}$ gradient indicates the existence of low-frequency (or long-period) noise in this accelerogram. The blue dashed lines in Figure 1 represent the lower and upper bounds of selected filter cut-off frequencies. The 20 filter cut-offs are generated in this range to obtain processed ground motion accelerograms. It can be inferred from this figure that the processed records with filter cut-off frequencies close to the lower bound include still more low frequency components. The accelerograms processed with filter cut-off frequencies close to the upper bound exhibit more gradual decay rates with respect to the $\mathrm{f}^{2}$ gradient. It is an indication of distortion of the low frequency content of the accelerogram.

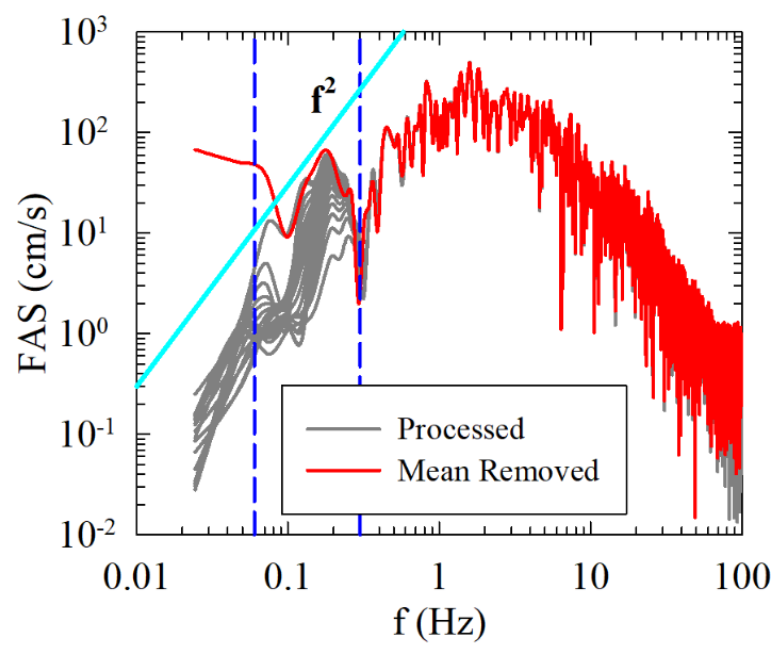

Figure 1. FAS of mean removed and processed accelerograms, and filter cut-off bandwidths (blue dashed lines) for Imperial Valley Earthquake, Bonds Corner Station record (15/10/1979 --Component $\left.230-\mathbf{M}_{\mathrm{w}}=6.5\right)$.

\section{Variation of Intensity Measures}

Intensity measure is known as the damaging potential of ground motions to the engineering structures. It becomes the subject of many studies in literature and different intensity measures have been defined for earthquake records. The most widely used intensity measures are the PGD (Peak Ground Displacement), PGV (Peak Ground Velocity), PGA (Peak Ground Acceleration), $\mathrm{PGV} / \mathrm{PGA}$ ratio and significant duration.

Seismic inputs to be used in dynamic analyses in which selection and classification of records is performed according to their intensity measures leads to differentiation of the obtained structural response [14-16]. In addition, the convenience of the intensity measures used in the selection of earthquake records for the type of structure under investigation is of great importance [17]. In literature, studies emphasize that nonlinear responses to be evaluated by means of dynamic analysis are sensitive to the peak ground motion amplitudes [18]. Also, it is recommended to consider the duration of strong motion as a parameter in the selection of records, since the longer the earthquake record, the higher the number of cycles. So, structural response can be a parameter of the duration of considered ground motions [19-21]. Therefore, characteristics of seismic inputs and processing approach for elimination of low frequency noise and also cut-off frequency interval change 
properties of this ground motion and structural response consequently. In this section, variation of intensity measures computed for different low cut-off frequencies is presented for selected pulse like and non-pulse like near fault ground motions. For this purpose, selected ground motions are high pass filtered firstly with twenty low cut-off frequencies and change in PGD, PGV, PGA, PGV/PGA and significant duration are investigated. In Figure 2. the variation of PGD, PGV and PGA values of Kocaeli-Yarimca record for both orthogonal horizontal components are illustrated as an example for raw data (unfiltered record), and two different cut-off frequencies. Here, it can be noted that PGD and PGV values of ground motion demonstrate a dramatic change after the low frequency noise is removed from the record. However, PGA value of both unfiltered and filtered motions are almost identical and not affected by filtering.
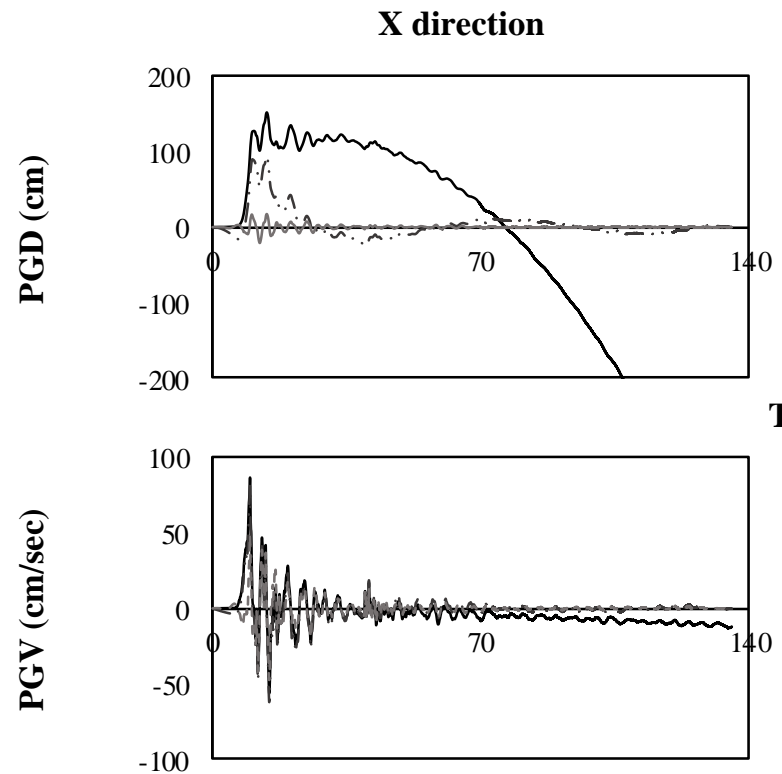

Time (sec)

Y direction
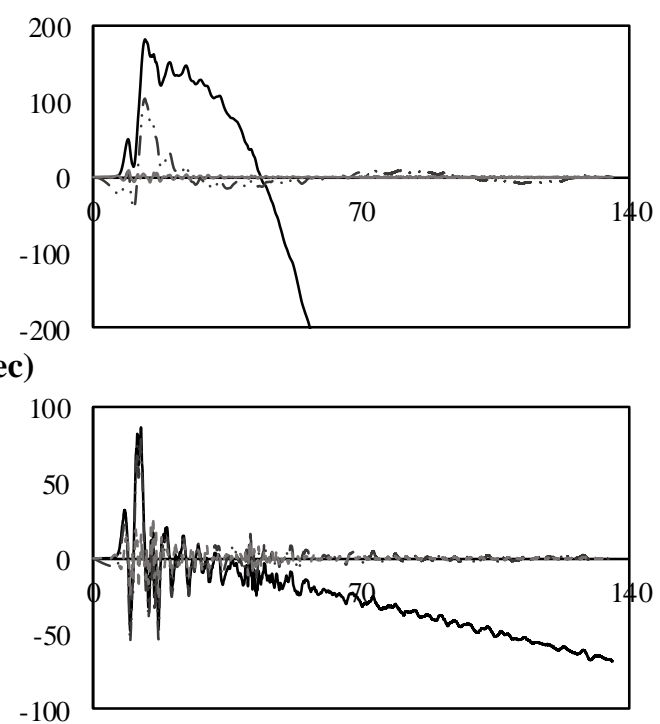

EQ\#

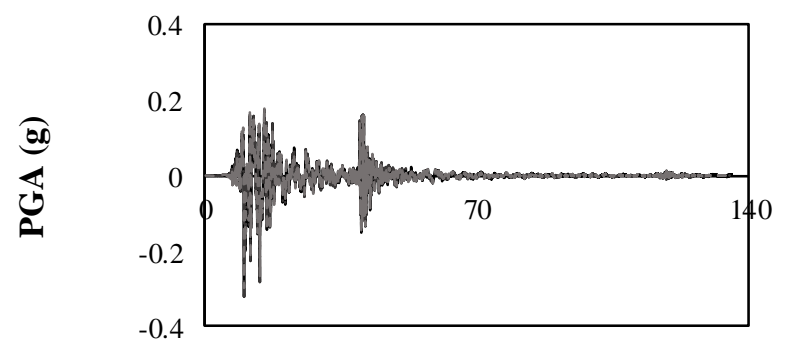

EQ \#

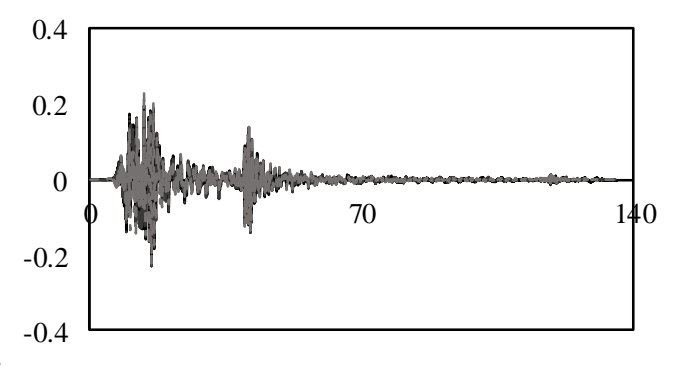

$\longrightarrow$ Raw data $\quad-\cdots-$. Filter \# $1 \quad$ Filter \# 20

Figure 2. PGD, PGV and PGA values of Kocaeli-Yarimca ground motion obtained from raw data, filtered records $\left(f_{c}{ }_{c}\right.$ and $\mathrm{f}_{\mathrm{c}}{ }^{20}$ filtering) and NGA-West2 records.

In the design or performance assessment of structures, engineers use the ground motion records obtained from strong motion databases in which records have already been filtered. One of widely cited ground motion database is the NGA-West2. In Figure 3. max-min values of intensity 
measures (PGD, PGV, PGA, PGV/PGA, and significant duration) evaluated after high-pass filtering for different cut-off frequencies and that of NGA-West 2 database for the same records are presented in a comparative manner In Figure 3. PGD values for selected and filtered ground motions show $99 \%$ increase and $94 \%$ decrease compared to that of NGA-West 2 records. It can be noted that PGD is the most influenced intensity measures of ground motion from filtering process.

PGV which represents the impulsive property of seismic input, is another intensity measure investigated in this study. In accordance with Figure 3., this parameter displays a variation between $\pm 14-69 \%$ compared to NGA-West2 records. Although the benefit of high-pass filtering is to remove the low frequency noise from ground motion records, it is important to be aware of the change in ground motion characteristics due to filtering. Since, improper filtering of low frequency content from raw data may lead unrealistic variation in impulsive properties of ground motion and misleading dynamic analysis results.

The max-min observed variation for PGA value in Figure 3. is $15 \%$ and 24\%, respectively. Although this variation is limited compared to those of PGV and PGD, it is still at an order that cannot be ignored. PGV/PGA values is the another most popular intensity measure in earthquake engineering which represents the damage potential of ground motion. As a result of high-pass filtering for twenty different cut-off frequencies, the amount of PGV/PGA values of filtered ground motions increase up to $76 \%$ and decrease $73 \%$ compared to that of records obtained from NGAWest2 database. Investigating the results, it can be seen that there is almost no variation for significant duration when different low cut-off frequency is considered with NGA-West 2 records.

\section{Conclusion}

In this paper, variation of ground motion intensity measures such as PGD, PGV, PGA, PGV/PGA and significant duration due to high-pass filtering is studies. For this purpose, a set of near fault earthquakes is selected, and ground motions are filtered with different low cut-off frequency intervals. The variations in considered intensity measures are discussed for each filtered seismic input and that of NGA-West 2 database record in a comparative manner. Obtained results shows that, changing the cut-off frequency of high pass filtering considerably changes the intensity measures of ground motion records, specially PGD, PGV and PGV/PGA values. Also, removing long period noise with high-pass filtering can change the ground motion impulsive property which can lead to unreliable spectral quantities and questionable structural responses when used in dynamic analyses. 
$\mathrm{X}$ direction
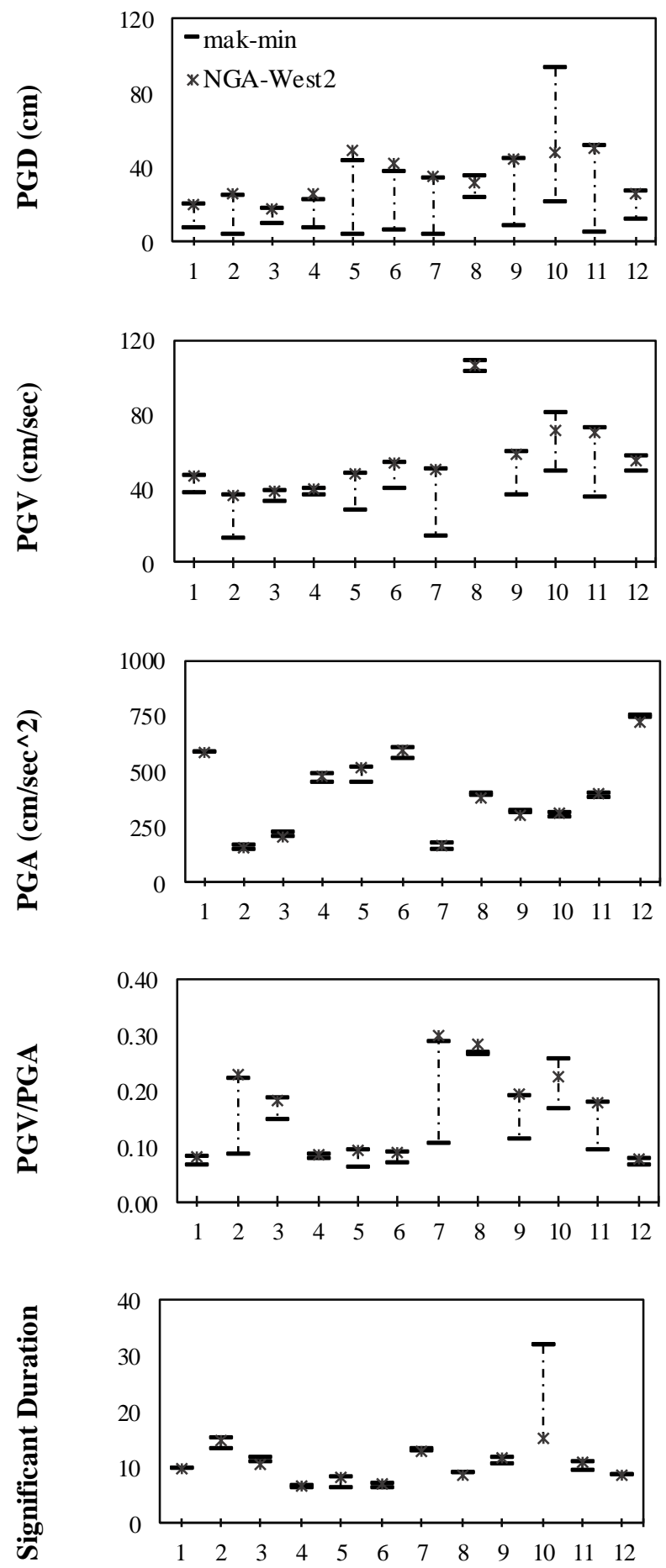

Y direction

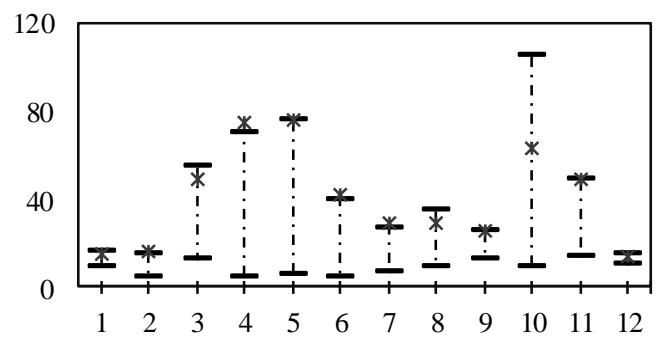

EQ \#

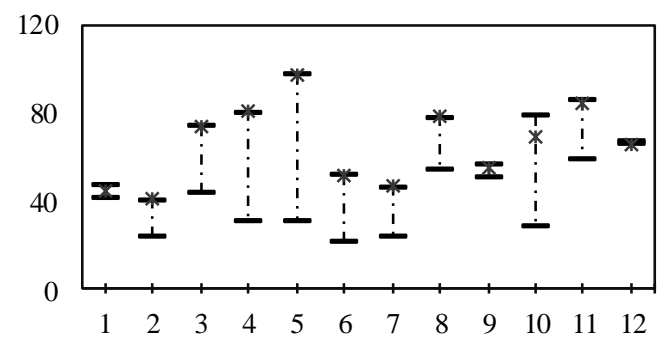

EQ\#

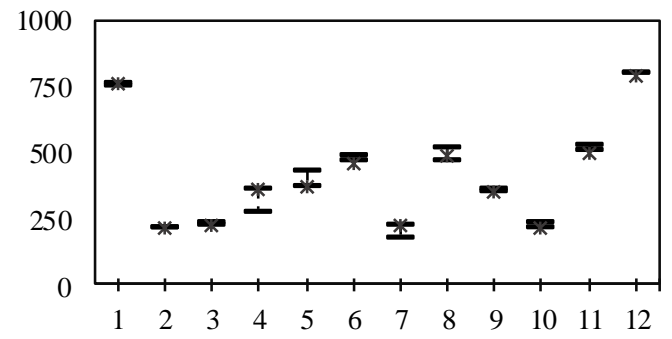

EQ \#

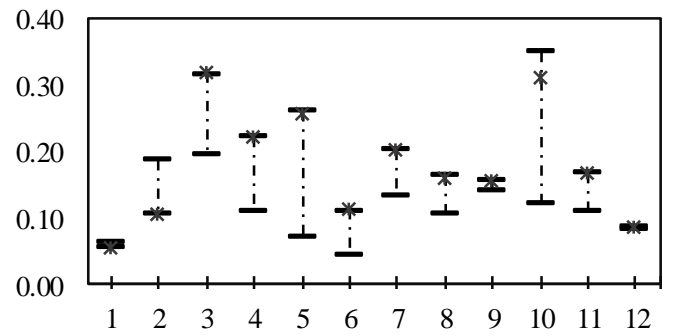

EQ\#

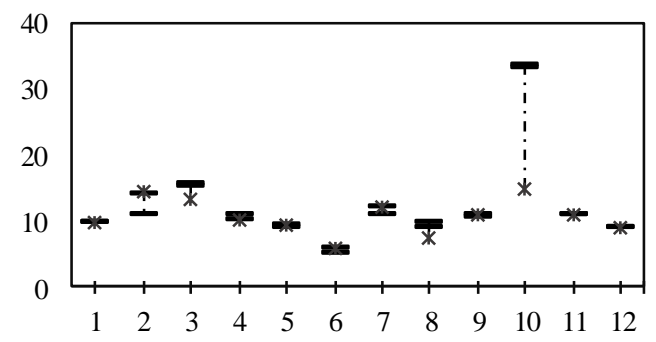

EQ\#

Figure 3. Comparison of selected ground motion intensity measures obtained from NGA-West2 database records and applied filtering process. 


\section{References}

[1] Yang S, Mavroeidis GP, Ucak A, Tsopelas P. Effect of ground motion filtering on the dynamic response of a seismically isolated bridge with and without fault crossing considerations. Soil Dynamics and Earthquake Engineering 2017; 92:183-191.

[2] Abrahamson, NA, Silva WJ. Empirical response spectral attenuation relations for shallow crustal eartqaukes. Seismological Reserach Letters 1997; 68:94-127.

[3] Boore, DM, Bommer JJ. Processing of strong-motion accelerograms: needs, options and consequences. Soil Dynamics and Earthquake Engineering 2005; 25:93-115.

[4] Akkar S, Bommer JJ. Influence of long-period filter cut-off on elastic spectral displacements. Earthquake Engineering and Structural Dynamics 2006; 35:1145-1165.

[5] Kale O. An empirical relationship based on high-pass filtering to estimate usable period range for nonlinear SDOF response. Master of Science Thesis, Middle East Technical University, The Graduate School of Natural and Applied Science, Ankara, 2009.

[6] Burks LS, Baker JW. Fling in near-fault ground motions and its effect on structural collapse capacity. Tenth US National Conference on Earthquake Engineering Frontiers of Earthquake Engineering July 2014.

[7] Buyco K, Roh B, Heaton TH. Effects of long-period processing on structural collapse predictions. Earthquake Spectra 2020; 8755293020936699.

[8] Zerva A, Liao S. Processing acceleration simulations, Proceedings of ICOSSAR, Tokyo, Japan, 2009.

[9] Falamarz-Sheikhabadi MR, Zerva A. Optimal corner frequency in high-pass filtering of strong ground motions and its effect on seismic intensity. Journal of Earthquake Engineering 2019; 1-31.

[10] Xue Y, Pu W, Matsuda K, Kasai K. Influence of high-pass filtering of near-fault earthquake record on the responses of base-isolated building. Soil Dynamics and Earthquake Engineering $2020 ; 135: 106182$.

[11] PEER Strong Motion Database (https://ngawest2.berkeley.edu/)

[12] Utility Software for Data Processing (USDP). Department of Civil Engineering, Middle East Technical University, Ankara, Turkey, 2008. available on internet at http://www.usdp.org/download.htm, last visited on June 2009.

[13] McKay MD, Conover WJ, Beckman RJ. A comparison of three methods for selection values of input variables in the analysis of output from a computer code. Technometrics 1979; 2:239-245. 
[14] Bommer JJ, Magenes G, Hancock J, Penazzo P. The influence of strong-motion duration on the seismic response of masonry structures. Bulletin of Earthquake Engineering 2004; 2(1):1-26.

[15] Haselton C, Baker J. Ground motion intensity measures for collapse capacity prediction: Choice of optimal spectral period and effect of spectral shape. 8th National Conference on Earthquake Engineering. San Francisco, California, April 18-22, 2006.

[16] Ye LP, Lu XZ, Ma QL, Cheng GY, Song SY, Miao ZW, Pan P. Study on the influence of post-yielding stiffness to the seismic response of building structures. 14th World Conference on Earthquake Engineering. Beijing, China, October 12-17, 2008.

[17] Avşar O, Ozdemir G. Response of seismic-isolated bridges in relation to intensity measures of ordinary and pulselike ground motions. Journal of Bridge Engineering 2013; 18(3): 250-260.

[18] Bommer JJ, Acevedo AB. The use of real earthquake accelerograms as input to dynamic analysis. Journal of Earthquake Engineering 2004; 8(spec01):43-91.

[19] Katsanos EI, Sextos AG, Manolis GD. Selection of earthquake ground motion records: A state-of-the-art review from a structural engineering perspective. Soil Dynamics and Earthquake Engineering 2010; 30(4):157-169.

[20] Bradley BA. Correlation of significant duration with amplitude and cumulative intensity measures and its use in ground motion selection. Journal of Earthquake Engineering 2011, 15(6):809-832.

[21] Raghunandan M, Liel AB. Effect of ground motion duration on earthquake-induced structural collapse. Structural Safety 2013; 41:119-133. 